\title{
Por uma Escola Leitora: relato de uma experiência aglutinadora da comunidade escolar em torno de uma missão comum
}

For a school reader: the story of a unifying experience of the school community around a common mission

\begin{abstract}
Suzene Furtado Fonseca de Oliveira Auxiliar da Biblioteca Escolar da Escola Municipal Presidente Tancredo Neves, Belo Horizonte - MG, estudante de Biblioteconomia na Escola de Ciência da Informação da Universidade Federal de Minas Gerais, escritora de livros infantis e juvenis. E-mail: suzeneffo@gmail.com
\end{abstract}

\section{Resumo}

Relata o planejamento, a execução, a ampliação e os resultados de projetos de formação de leitores em uma biblioteca escolar municipal de Belo Horizonte, Minas Gerais. Os projetos foram desenvolvidos em conformidade com o Programa de Bibliotecas Escolares da Prefeitura de Belo Horizonte e com o Plano Nacional do Livro e Leitura, e seguiu a estrutura conceitual de Montiel-Overall no norteamento da colaboração dos auxiliares de biblioteca com o corpo docente.

Palavras-chave: Biblioteca escolar. Projeto de leitura. Relato de experiência.

\begin{abstract}
Reports the planning, the implementation, the expansion and the outcomes of projects for educating readers in a school library of a government school in Belo Horizonte, Minas Gerais, Brazil. The projects were developed in accordance to the School Library Program of the City of Belo Horizonte and to the National Book and Reading Plan, and followed the conceptual structure of Montiel-Overall to guide the process of collaboration of library assistants with faculty.
\end{abstract}

Keywords: School library. Reading project. Experience report. 


\section{Introdução}

A Rede Municipal de Educação de Belo Horizonte, ao implantar em 1997 o Programa Escola Plural, visando à aprendizagem e inserção sociocultural dos alunos pela vivência e pela convivência cidadã, desenvolveu diversas ações para a efetivação dessa nova proposta pedagógica. Uma das estratégias foi a criação do Programa de Bibliotecas Escolares com o objetivo de revitalizar as bibliotecas das escolas municipais proporcionando diretrizes, meios e recursos para que estas passassem a integrar o projeto político pedagógico de suas respectivas unidades em seu contexto particular, formando alunos e professores leitores e pesquisadores.

A Escola Municipal Presidente Tancredo Neves (EMPTN) situada na Regional Venda Nova, possui 823 alunos estudantes do Terceiro Ciclo do Ensino Fundamental e do Ensino Médio; alguns destes, participantes do projeto de Escola Integrada com desenvolvimento de atividades diversas no contra-turno. Com um espaço físico privilegiado (três quadras, sendo uma delas coberta; auditório; laboratório de informática; cantina espaçosa etc.) e mais de 50 funcionários entre professores e técnico-administrativos, a EMPTN é referência na comunidade em que está inserida, com ela dialogando principalmente por meio da biblioteca escolar, frequentada para fins de pesquisa e leitura literária. A Biblioteca Carlos Drummond de Andrade, por ter essa característica de atendimento à comunidade, é definida como Biblioteca-Polo, sendo coordenada por uma Bibliotecária graduada em Biblioteconomia e contando com um Auxiliar de Biblioteca por turno.

A Biblioteca Carlos Drummond de Andrade possui um espaço de $180 \mathrm{~m}^{2}$ e conta com acervo de mais de 10.000 documentos, dentre eles: livros de gêneros diversos, obras de referência, jornais, revistas, gibis, mapas, globos terrestres, CDs, DVDs e jogos pedagógicos; além de 2 computadores para uso exclusivo dos funcionários. $\mathrm{O}$ ambiente interno possui mesas e cadeiras suficientes para acomodar uma classe inteira (em média 35 alunos) além de espaço para atendimento e circulação de outros grupos de usuários. O ambiente externo é dotado de mesas e bancos com igual capacidade de atendimento. A biblioteca presta serviços regulares de consulta local, empréstimo domiciliar, atividades de incentivo e promoção da leitura e orientação à pesquisa escolar.

Ao tomar posse como Auxiliar de Biblioteca na EMPTN, em dezembro de 2012, buscou-se inteirar a respeito do perfil da escola, de seu contexto e práticas pedagógicas a fim 
de estudar meios para a efetivação dos objetivos do Programa de Bibliotecas Escolares da Rede Municipal de Educação de Belo Horizonte. Somente em fevereiro de 2013 iniciou-se contato com os usuários da biblioteca, por meio de visitas orientadas a este espaço e conversas informais no ambiente escolar. Observou-se durante esse período o funcionamento da biblioteca, a frequência e as práticas de leitura do público-alvo, os problemas e as iniciativas para resolvê-los, as propostas e projetos bem sucedidos e os insucessos. Identificou-se a necessidade de criação de projetos simultâneos e articulados capazes de apresentar inovações, mas também aproveitar experiências anteriores bem sucedidas e a urgência de desenvolvimento de uma prática colaborativa e cooperativa que reunisse os Auxiliares de Biblioteca dos diferentes turnos em torno de propósitos comuns.

Juntamente com o Auxiliar de Biblioteca Hilton Soares Cardoso Junior iniciou-se o projeto intitulado "Por uma Escola Leitora", cuja sustentação teórica decorre das discussões de diferentes autores, tais como Kuhlthaul (2002) e Campello (2009), e de documentos oficiais como o Programa de Bibliotecas Escolares da Prefeitura de Belo Horizonte (2011) e o Plano Nacional do Livro e Leitura (2010).

O Plano Nacional do Livro e Leitura (PNLL) é uma iniciativa conjunta do Ministério da Cultura e do Ministério da Educação que conta com a participação de instituições comprometidas com a promoção da leitura e de representantes de diversos setores da sociedade nos debates que delinearam sua estrutura. Para alcançar o objetivo de formação de um Brasil leitor, o PNLL se estruturou em quatro eixos de ação:

1. Democratização do acesso;

2. Fomento à leitura e à formação de mediadores;

3. Valorização da leitura e comunicação;

4. Desenvolvimento da economia do livro.

Dentro de cada eixo foram definidas linhas de ação para que os envolvidos no processo de promoção do livro e da leitura pudessem concentrar esforços e recursos nas prioridades do setor. Em consonância com as diretrizes estabelecidas pelo PNLL, e imbuídos do compromisso de fazer do Brasil um país leitor, deu-se início ao projeto "Por uma Escola Leitora". 


\section{Fundamentos teóricos e articulação institucional do projeto "Por uma Escola Leitora"}

O Programa de Bibliotecas Escolares da Prefeitura Municipal de Belo Horizonte tem como eixos norteadores do Programa: a informatização do sistema; a melhoria do acervo; a formação de pessoal e o desenvolvimento de projetos de incentivo à leitura. Considerou-se este último e os seguintes objetivos específicos a ele relacionados:

- Promoção do atendimento da biblioteca ao coletivo escolar e também à comunidade situada no entorno da escola em suas demandas de informação e leitura;

- Desenvolvimento e proposta de programas de leitura a partir da integração da biblioteca com os projetos pedagógicos da escola;

- Desenvolvimento e proposta de projetos que ajudem a tornar a biblioteca um local de múltiplas leituras de informação, de formação e de expressão da cultura.

Para seguir tais rotas e alcançar tais metas, mesmo com as limitações funcionais do cargo de Auxiliar de Biblioteca adotou-se por base a estrutura conceitual da professora norteamericana Patrícia Montiel-Overall (citada por CAMPELLO, 2009) que define o nível de colaboração do Bibliotecário na escola por meio de quatro níveis de ação:

- Coordenação;

- Cooperação;

- Instrução integrada;

- Currículo integrado.

Percebeu-se que estes graus de colaboração poderiam nos orientar e dar sustentação ao nosso propósito de exercer na escola, mesmo como Auxiliares de Biblioteca, relevante papel educativo. No início deste trabalho identificou-se no primeiro nível da estrutura conceitual, desenvolvendo funções específicas, esporádicas e independentes no apoio aos professores. Constatar esta realidade levou-nos a pensar um meio de ampliar nosso contato com os professores e demais membros da comunidade escolar, fazendo-se conhecidos por eles e oferecendo parcerias. Assim, desta reflexão, surgiu uma das vertentes do projeto "Por uma Escola Leitora". 


\subsection{Projeto "Livros na Cesta"}

Reconheceu-se que seria praticamente impossível criar vínculos se permanecêssemos encerrados no espaço da biblioteca, já que a frequência de professores e funcionários da EMPTN à biblioteca escolar era muito reduzida devido à falta de tempo ou ao desconhecimento do acervo e de sua disponibilidade para atender demandas pessoais e didáticas. Decidiu-se elaborar estratégias capazes de levar este público à apropriação da biblioteca como espaço de leitura, cultura, lazer, informação e convivência.

Assim, definiu-se como objetivos para este projeto:

- Facilitar o acesso ao acervo da biblioteca para professores e funcionários;

- Apresentar novas aquisições e títulos do acervo;

- Dialogar com professores e funcionários sobre a prática de leitura;

- Descobrir o gosto de cada leitor;

- Romper com elementos dificultadores para realização de empréstimos por parte dos professores e funcionários, como a falta de tempo para ir à biblioteca;

- Conscientizar os usuários que a biblioteca é parte do espaço escolar sendo, simultaneamente, de uso coletivo e particular.

O projeto "Livros na Cesta" recebeu este nome a fim de reforçar por apelos visual e sonoro a memorização do dia da semana em que os Auxiliares de Biblioteca iriam ao encontro de professores e funcionários da escola com duas cestas repletas de livros para empréstimo - obviamente, às sextas-feiras. O horário dos encontros com os grupos de profissionais que compõem a comunidade escolar foi por eles determinado conforme seu momento de maior disponibilidade. Às sextas-feiras, tradicionalmente, a biblioteca fica fechada para organização interna, o que permitiu o atendimento a todos os leitores-alvo deste projeto sem alterar a rotina dos alunos com a biblioteca. Inicialmente, apenas os profissionais do turno da manhã participariam, mas há expansão prevista para os outros turnos.

Esse projeto segue as seguintes linhas de ação descritas no PNLL: a Melhoria do Acesso ao Livro e a Outras Formas de Expressão da Leitura (Eixo 1), a Formação de Mediadores de Leitura e Projetos Sociais de Leitura (Eixo 2). 
Esperava-se com o projeto o aumento contínuo de empréstimos para professores e funcionários e a valorização e adoção da biblioteca como espaço individual e coletivo de cultura, informação e lazer no espaço escolar. Já no primeiro dia de desenvolvimento do projeto obtiveram-se bons resultados, realizando 28 empréstimos. A média atual é de 18 empréstimos semanais para os profissionais do turno da manhã; o que não representa uma queda já que ocorreu aumento da frequência à biblioteca - para consulta, empréstimos, elaboração de atividades em parceria ou agradáveis conversas literárias.

Os alunos também estão sendo influenciados, indiretamente, pelo projeto. Realizam um verdadeiro cortejo acompanhando os Auxiliares de Biblioteca à Sala dos Professores no horário do recreio. Querem saber o que eles lêem, quem pegou qual livro e por vezes querem reservá-los para leitura posterior. Acham graça e comentam que da porta de entrada à porta dos fundos da escola quase todos os professores e funcionários têm, às sextas-feiras, um livro em mãos.

O projeto "Por uma Escola Leitora" apresenta ainda outras vertentes, conforme será descrito nos tópicos posteriores.

\subsection{Projeto "Mídia Amiga"}

É mundialmente comentado o interesse de crianças e adolescentes por redes sociais e o tempo que dedicam a navegações na internet para apreciar e compartilhar conteúdos. $\mathrm{O}$ projeto "Mídia Amiga" tem por objetivos:

- Criar um perfil da Biblioteca Carlos Drummond de Andrade no Facebook com informações variadas sobre livros, leitura e cultura em geral; e "Página" vinculada a este perfil;

- Dialogar com os alunos sobre práticas de leitura e diversas manifestações culturais, utilizando para isso as redes sociais;

- Selecionar material informacional de qualidade e com linguagem acessível ao público de 11 a 18 anos;

- Auxiliar o comportamento informacional dos adolescentes na rede;

- Postar as indicações literárias decorrentes das experiências da própria comunidade escolar. 
Visando um diálogo maior da Biblioteca Carlos Drummond de Andrade com seus principais usuários - os alunos da EMPTN - foi realizada uma pesquisa a fim de melhor compreender como ocorre o uso da internet e das redes sociais por este grupo, e como a escola pode formar leitores por meio dessas mídias.

A Pesquisa TIC Kids Online Brasil 2012 (2013), realizada pelo CETIC.br (Centro de Estudos sobre Tecnologias da Informação e da Comunicação) com o objetivo de quantificar uso e hábitos da população brasileira de 9 a 16 anos usuária da Internet para definição de oportunidades e riscos relacionados a esta prática, expôs os seguintes dados:

- $70 \%$ das crianças e adolescentes brasileiros com idade entre 9 e 16 anos, que usam internet, têm um perfil próprio em uma rede social;

- A presença dos jovens nessas redes aumenta de acordo com a faixa etária: $42 \%$ dos usuários de 9 a 10 anos têm o próprio perfil, proporção que atinge $83 \%$ na idade entre 15 e 16 anos;

- $47 \%$ dos brasileiros entre 9 e 16 anos usam a internet todos os dias ou quase todos os dias;

- $42 \%$ acessam a internet na escola, $40 \%$ em casa, $35 \%$ na lanhouse e $18 \%$ no celular.

Outro dado importante, este revelado pelo Ranking Alexa (mediação da empresa Amazon com dados abertos) é que o Facebook, desde o ano de 2011, é a rede social mais visitada no Brasil (CASTRO, 2012; MATSUKI, 2012).

A partir da análise dessas pesquisas definiu-se como valiosa ferramenta para o estabelecimento de diálogo com o público adolescente e a veiculação de informações relevantes sobre livro, leitura e expressões culturais diversas, o Twitter, o Blog e o Facebook.

O Twitter para instantâneos, "informações-relâmpago". O Blog para textos mais extensos e que permitem consulta freqüente como livros existentes no acervo, suas sinopses e suas capas. O Facebook para expor no perfil agenda cultural e painel de dicas de leitura, com co-participação dos alunos na construção de material informativo; e a "Página" com poemas de Drummond ilustrados.

O material a ser publicado é analisado e discutido pelos administradores das mídias, quanto à relevância, qualidade e contextualização. Há no mínimo uma atualização semanal 
dos conteúdos. A atualização do Twitter e do Blog corre a cargo de Hilton Júnior, que já os havia criado anteriormente. Os conteúdos do Facebook e a "Página" são administrados pela Auxiliar. Há participação dos alunos na criação de postagens, aprovações e compartilhamento de conteúdos, desenvolvendo pela Web práticas de leitura e escrita.

Foram criados os seguintes endereços eletrônicos para a Biblioteca Carlos Drummond de Andrade:

- Twitter: @bibliocantodeideias

- Blog: https://bibliocantodeideias.blogspot.com

- Facebook: http://www.facebook.com/biblioteca.carlosdrummonddeandrade

- Página: http://facebook.com/pages/Biblioteca-Carlos-Drummond-de-Andrade

- E-mail: bibliocantodeideias@gmail.com

Este projeto segue as seguintes linhas de ação descritas no PNLL: Melhoria do acesso ao livro e a outras formas de expressão da leitura, Incorporação e uso de tecnologias de informação e comunicação (Eixo 1), Publicações impressas e outras mídias dedicadas à valorização do livro e da leitura (Eixo 3).

A avaliação do projeto se dará quantitativamente pelas estatísticas das publicações concedidas pelo sistema aos administradores do Twitter, do Blog, do Perfil e da "Página"; por exemplo: interações, comentários e compartilhamentos; o que permitirá, além da avaliação, o direcionar dos assuntos abordados. Qualitativamente a avaliação decorre da reação de alunos, professores e funcionários às postagens.

$\mathrm{Na}$ execução deste projeto encontrou-se como dificuldades o controle do Facebook sobre o crescente aumento de usuários, bloqueando as adições de "amigos", a dificuldade dos alunos em acessar a internet fora do ambiente escolar, a idade ainda insuficiente de muitos deles para a construção de um perfil próprio na rede e a necessidade de coletarmos autorização dos pais para exibição de fotos em que seus filhos aparecem.

A terceira vertente do projeto "Por uma Escola Leitora" estabelece parceria com professora da escola. 


\subsection{Projeto "Poesia na Escola é Todo Dia"}

Apresentar o gênero poesia aos alunos da EMPTN a fim de sensibilizá-los e preparálos para formas mais complexas de linguagem é uma iniciativa da professora Dulce Mara Lopes Reis, que leciona Língua Portuguesa para as turmas do sétimo ano no turno da manhã. Para alcançar seus objetivos, a professora propôs parceria com a Biblioteca e desde o mês de março/2013 o referido projeto é desenvolvido com sucesso, ininterruptamente.

Este projeto segue as seguintes linhas de ação descritas no PNLL: Distribuição de livros gratuitos (como premiação aos alunos que cumprirem as propostas da semana), Melhoria do acesso ao livro e a outras formas de expressão da leitura (Eixo 1/PNLL Democratização do acesso); Projetos sociais de leitura (Eixo 2/PNLL - Fomento à leitura e à formação de mediadores), Ações para criar consciência sobre o valor social do livro e da leitura (Eixo 3/PNLL - Valorização da leitura e comunicação).

A fim de formar leitores sensíveis, conscientes, críticos e apreciadores do gênero poesia, capazes de interpretar as outras linguagens presentes em seu ambiente social, foram estabelecidos os seguintes objetivos específicos:

- Apresentar aos alunos do $7^{\circ}$ ano da Escola Municipal Presidente Tancredo Neves, o gênero literário Poesia;

- Realizar atividades de descoberta de autor, ilustrador, título e editora;

- Promover atividades envolvendo a visita de escritores e ilustradores à escola.

No desenvolvimento desse projeto passou-se, segundo a estrutura conceitual de Patrícia Montiel-Overall, do nível de Coordenação para o grau de Cooperação com pouco planejamento conjunto e preponderância da ação da professora, tendo os Auxiliares conhecimento dos objetivos por ela propostos e das atividades reservadas a cada um neste processo e listadas a seguir:

\section{Ações dos Auxiliares de Biblioteca:}

a) Selecionar a cada quinzena um poema para ser trabalhado com os alunos;

b) Propor um desafio referente ao poema; a resposta certa sorteada é premiada com um kit contendo 2 livros, 2 revistas de passatempo, lápis, borracha, caneta, tesoura sem ponta, marcador de livro e 2 bombons; 
c) Montar um painel no pátio da escola com o poema selecionado ilustrado, o enigma e dicas;

d) Selecionar material para montagem do kit de premiação e montar o kit;

e) Enfeitar a urna;

f) Divulgar a atividade;

g) Realizar no pátio o sorteio de uma resposta correta por turno.

\section{Ações da Professora Dulce Mara:}

a) Trabalhar o poema em sala de aula com os alunos;

b) Divulgar a atividade;

c) Realizar cerimônia de entrega de prêmios;

d) Promover atividades complementares: oficina literária, manhã de autógrafo, etc.

Esperava-se resultados a longo prazo como a sensibilização dos alunos, o desenvolvimento do gosto estético e a apreciação do gênero literário poesia, auxiliando a leitura que fazem do mundo e de si mesmos, bem como a compreensão de outros gêneros textuais; porém, o êxito imediato do projeto em aspectos outros surpreendeu.

Antes destinado apenas aos alunos da professora Dulce Mara, o projeto "Poesia na Escola é Todo Dia" teve grande repercussão na escola. Alunos de todas as séries e turnos envolveram-se na atividade. Professores, funcionários e membros da comunidade interessaram-se pelo projeto e solicitaram o direito à participação.

A estrutura conceitual de Patrícia Montiel-Overall apontou nova mudança de grau. $\mathrm{O}$ envolvimento dos Auxiliares de Biblioteca com a professora aumentou e os papéis por estes assumidos foram alterados elevando o nível de colaboração à Instrução Integrada. Assumindo o papel educativo que julgou-se pertinente, atuou-se na reformulação do projeto diante do novo contexto, ampliando seu alcance. Além do planejamento e implementação das atividades em conformidade com os objetivos da professora oportunizou-se a orientação e o treinamento dos alunos e comunidade escolar no processo de desenvolvimento de habilidades informacionais dentro do espaço biblioteca.

Desejosos de solucionar o desafio do poema, o público-alvo recorreu à biblioteca para buscar informações e dicas e solicitou a orientação dos Auxiliares. Assim sendo, aproveitou- 
se a oportunidade para apresentá-los às estantes de poemas, onde puderam pesquisar a resposta do enigma qual fosse este: o nome do autor ou do ilustrador, o título, uma palavrachave ou frase. A conversa com os diversificados leitores originou a indicação de livros de seu interesse e a realização de empréstimos.

O projeto movimentou a comunidade escolar como uma grande brincadeira. Tornou-se assunto nas salas de aula, nos corredores, na Sala dos Professores, em todos os ambientes escolares, conforme diversos depoimentos que chegaram aos Auxiliares. Recebeu-se total apoio da Diretora Lívia Fernandes de Oliveira da Costa Cunha e da Vice-Diretora Viviene Soares de Oliveira que se fizeram parceiras do projeto disponibilizando mais recursos materiais para o aumento do número de premiações e apoiando estruturalmente a organização quinzenal de verdadeiras festas de entrega de prêmios no horário do recreio. Confirmando o reconhecimento da relevância do projeto para toda a escola e sua pertinência a todas as disciplinas, a direção permitiu a ampliação do tempo destinado ao recreio em 15 minutos nos dias de sorteio.

\section{Considerações finais}

No período de observação e coleta de dados para definição do perfil da escola, de seu contexto e práticas pedagógicas, foram ouvidos comentários diversos de alunos das diferentes turmas e turnos que definiam o ato de ler como sendo um processo individual, monótono e de resultados pouco compartilhados com seu grupo de convívio. Diante disso percebeu-se que para obter êxito no desenvolvimento de projetos de incentivo à leitura na Escola Municipal Presidente Tancredo Neves, deveria ser demonstrado aos alunos e a toda a comunidade escolar o quanto a leitura vem a ser uma ação prazerosa passível de ser coletivizada.

Estimou-se que uma única ação de desenvolvimento da prática de leitura não seria suficiente para o alcance dos objetivos definidos pelo Programa de Bibliotecas da Região Metropolitana de Belo Horizonte, como o atendimento às demandas informacionais e literárias da comunidade escolar e circunvizinha, a integração com os projetos pedagógicos da escola e a distinção da biblioteca como local de múltiplas leituras de informação, de formação e de expressão da cultura. A fim de solucionar este entrave, começou-se a idealizar ações múltiplas, diferenciadas e simultâneas, capazes de se relacionar (apesar de à primeira vista parecerem interdependentes), aperfeiçoando cada uma delas - individualmente e em conjunto 
- o desenvolvimento de um projeto único agregador dos objetivos antes descritos. A grandiosidade do desafio gerou o nome do projeto unificador e o reconheceu como missão: "Por uma Escola Leitora".

Para a execução desta missão fez-se imprescindível a parceria com o Auxiliar de Biblioteca Hilton Soares Cardoso Junior que permitiu um somatório de energia, disposição, habilidades, conhecimentos e objetivos complementares. A estrutura conceitual da professora norte-americana Patrícia Montiel-Overall nos auxiliou na definição do nível de colaboração em que se encontrava e no estabelecimento de diretrizes para se alcançar o grau desejado.

Tão logo o projeto, em suas diversas faces, fez-se notar à comunidade escolar, obtevese dos professores e funcionários estimulante apoio e reconhecimento, o que fez os Auxiliares de Biblioteca sentirem-se participantes do processo educativo. A complementação ao andamento do projeto pela direção e coordenação da escola foram um demonstrativo de que a missão não é apenas dos Auxiliares, mas de todos os interessados no trabalho "Por uma Escola Leitora".

Empenhados no alcance dos objetivos definidos para as bibliotecas escolares municipais de Belo Horizonte apresentou-se o projeto na íntegra à Coordenadora do Programa de Bibliotecas Escolares Carolina Teixeira de Paula e à Vice-Coordenadora Leila Cristina Barros. Obteve-se apoio de ambas, acompanhamento e aprovação.

O projeto "Por uma Escola Leitora" foi, portanto, avaliado e aprovado pelos alunos e por toda a equipe pedagógica administrativa de algum modo a ele relacionada. Novas vertentes já se originam como propostas do próprio corpo docente da EMPTN.

As ideias apresentadas e discutidas no " 1 º Fórum Brasileiro de Biblioteconomia Escolar: pesquisa e prática" certamente contribuirão para a continuidade e expansão do projeto "Por uma Escola Leitora" na medida em que permitirão o renovar da prática pelo conhecimento de outras propostas e experiências no contexto das bibliotecas escolares em realidades semelhantes ou totalmente diversas. Tendo o privilégio de participar deste momento de reflexão e coletivização de objetivos, metodologias e práticas, identificou-se este evento como grande contribuinte para a formação da Auxiliar como Bibliotecária. Será portavoz das reflexões suscitadas para os colegas Auxiliares de Biblioteca e toda a equipe pedagógico-administrativa da EMPTN, tendo a certeza de que a partir deste 
compartilhamento outras tantas ideias e projetos educacionais colaborativos no espaço escolar serão estimulados.

\section{Referências}

BELO HORIZONTE. Prefeitura Municipal. Manual de organização das bibliotecas escolares. Belo Horizonte: Prefeitura de Belo Horizonte, 2011.

BRASIL. Plano nacional do livro e da leitura. Brasília: Ministério da Cultura; Ministério da Educação, 2010. Disponível em: <http://189.14.105.211/conteudo/pnll_download.pdf $>$. Acesso em: 04 mar. 2013.

BRASIL. Retratos da Leitura no Brasil. 2012. Disponível em:

$<$ http://www.prolivro.org.br/ipl/publier4.0/dados/anexos/2834_10.pdf >. Acesso em: 04 mar. 2013.

CASTRO, D. Brasil é o país mais ativo do mundo do Facebook. 2012. Disponível em: $<$ http://www.ebc.com.br/tecnologia/2012/10/brasil-e-o-pais-mais-ativo-do-mundo-nofacebook>. Acesso em: 10 jan. 2013.

CAMPELLO, B. S. Colaboração do bibliotecário com a equipe pedagógica. In: Letramento Informacional: função educativa do bibliotecário na escola. Belo Horizonte: Autêntica, 2009. p. 53-62.

KUHLTHAU, C.C. et al. Como usar a biblioteca na escola: um programa de atividades para o ensino fundamental. Belo Horizonte: Autêntica, 2002.

MATSUKI, E. Saiba quais são as cinco redes sociais mais acessadas no Brasil. 2012.

Disponível em: <http://www.ebc.com.br/tecnologia/2012/09/saiba-quais-sao-as-cinco-redessociais-mais-acessadas-do-brasil >. Acesso em: 10 jan. 2013.

TIC Kids Online Brasil 2012: pesquisa sobre o uso da Internet por crianças e adolescentes. São Paulo: Comitê Gestor da Internet no Brasil, 2013. Disponível em: $<$ http://www.cetic.br/publicacoes/2012/tic-kids-online-2012.pdf $>$. Acesso em: 15 jun. 2013. 